\title{
Supplementary Part: \\ Disordering Disorder as a Route to a Higher Order: Incoherent Crystallization of Apatite through Amorphous Precursors
}

\author{
Vuk Uskoković ${ }^{1, *}$ \\ ${ }^{1}$ Department of Mechanical and Aerospace Engineering, University of California, Irvine, CA 92697, USA \\ *Corresponding author: vuk21@yahoo.com; vuskokov@uci.edu
}

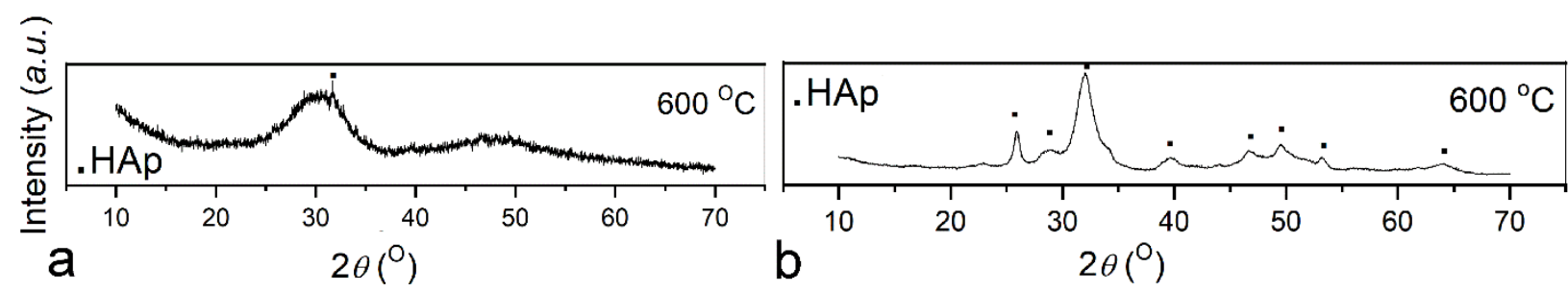

Fig.S1. XRD patterns of fresh ACP (a) and ACP aged up to the point of its transformation to HAp (b) after annealing at $600{ }^{\circ} \mathrm{C}$. The sharper HAp reflection in (a) than in (b) indicates a higher crystallinity of the HAp component in the powder that started off as fresh ACP than in the powder that started off as poorly crystalline HAp.

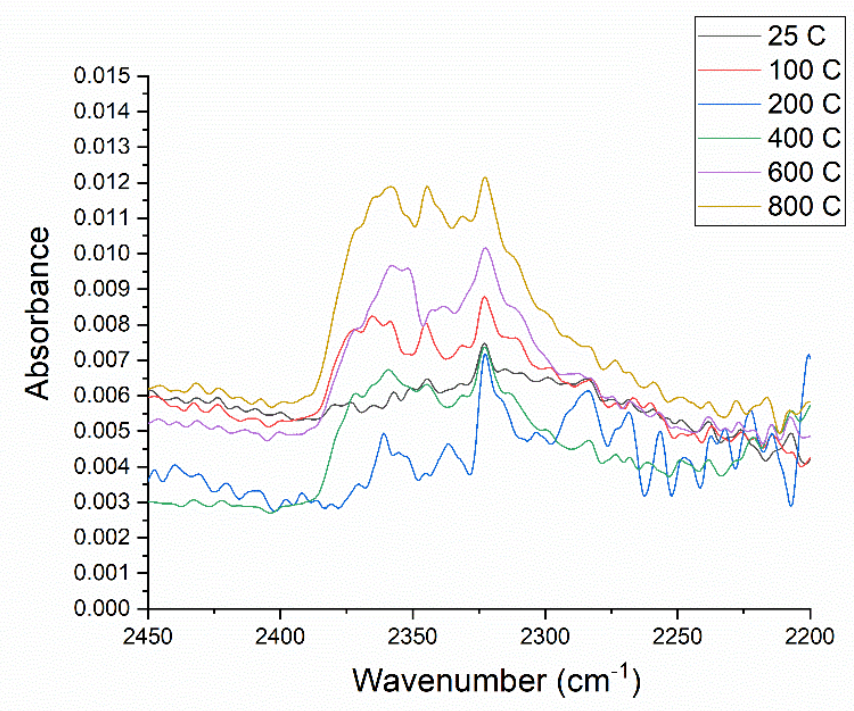

Fig.S2. FTIR spectrum of the CP powder produced by annealing ACP to $800{ }^{\circ} \mathrm{C}$ in the $2200-2450 \mathrm{~cm}^{-1}$ range, focusing on the triplet peaking at $2323.2 \mathrm{~cm}^{-1}$ that may have originated from the $\mathrm{O}-\mathrm{H}(\mathrm{P})$ stretch. 